\title{
Algunas precisiones sobre el sistema fiscal romano
}

\author{
Pilar Fernández Uriel *
}

Los tributos, tasas y demás cargas fiscales han sido medidas económicas y políticas tomadas por las distintas administraciones estatales a lo largo de los tiempos. Medidas sin duda indispensables para mantener las necesidades de los mismos, pero también impopulares que caían sobre la población con mayor o menor crudeza o acierto y siempre parecían excesivas.

Además, la resistencia al impuesto ha sido común en todas las épocas y el ciudadano o habitante de cualquier Estado siempre ha intentado pagar lo menos posible, pues los fraudes fiscales han existido siempre y el enfrentamiento entre los contribuyentes y los recaudadores, también.

Ya en la Antigüedad se puede comprobar los esfuerzos de funcionarios y gobernantes para evitar el fraude, la evasión y demás delitos fiscales. Ha sido incesante la búsqueda de bases seguras (censos, registros, leyes...) que garantizaran lo más correctamente posible el cobro de los impuestos.

Roma en modo alguno fue una excepción, es más, tal vez podamos considerar al Estado Romano como el final del camino de esta evolución de asegurar el sistema fiscal de los distintos gobiernos a lo largo del Mundo Antiguo y la base donde se asientan los sitemas tributarios de nuestra cultura occidental.

El Estado Romano supo desde los inicios de su expansión imperialista dotarse de una estructura administrativa y financiera suficientemente efectiva. Sería conveniente señalar aquí que en nuestra sociedad actual esta organización parece rudimentaria. Por ello nos asombra que con una administración y estructura fiscal de tal simpleza y características, fueran capaces de dirigir y sostener un Imperio de tales dimensiones. $Y$ asi fue,

* Departamento de Prehistoria e $H^{a}$ Antigua. UNED. 
este magno Imperio fue gobernado y dominado desde Roma durante más de ocho siglos.

Una de las posibles explicaciones que ofrecemos los historiadores sea, posiblemente, que el Estado Romano tenía unas exigencias claras y simples:

- Mantener la ley y el orden

- Recaudar impuestos

No se buscaban grandes objetivos ni económicos ni ideológicos ni sociales. Siempre se ha repetido la ya manida idea de que Roma no se inmiscuyó en la vida social y espiritual de sus súbditos siempre que estos cumplieran ambos objetivos: No se alterara la paz y se pagaran los impuestos debidos al Estado 1.

El sistema fiscal romano republicano no era uniforme, no estaba normalizado y adolecía de una política fiscal clara y organizada. Su supervisión era insuficiente y experimentó pocos cambios durante el Alto Imperio.

Durante el Principado romano, se adoptó en gran parte el sistema tributario republicano y en las provincias orientales continuó prácticamente la estructura fiscal de los reinos helenísticos anexionados a Roma. Es decir, en la mayoría de las veces se respetaron y continuaron las tributaciones anteriores a su anexión a Roma, limitándose a ampliarlo y adaptar las mismas a las nuevas necesidades.

Tan sólo se tomaron dos innovaciones:

- Se eliminaron gradualmente las compañías privadas de recaudadores ("Publicani») para el cobro de impuestos directos y más tarde de indirectos, pasando esta misión a manos de funcionarios que, por lo general fueron más efectivos.

- Se elaboró un cuidadoso censo de los súbditos del Imperio.

Los objetivos económicos y políticos que debian cubrir estos impuestos eran pocos y básicos, aunque no nos atreveríamos a calificarlos ni de li-

Sobre el Imperialismo romano y sus distintos aspectos hay una abundante bibliografía. Ver entre otros: HARRIS, w.v.: Guerra e Imperialismo en la Roma republicana. 327-70 a.C., Madrid, 1979; MUÑoz, F.: Los inicios del Imperialismo romano. La política exterior romana entre la primera, y la segunda Guerra Púnica Universidad de Granada, 1986; L'aidéologie de I'Imperialisme romain, Actes du Colloque de Dijon, París, 1974; Roma y las provincias. Realidad administrativa $\theta$ ideologia imperial, J. GonzÁl.EZ ed., Madrid 1944. 
mitados ni de livianos. Al contrario, debian cubrir importantes y costosas necesidades del Estado:

- Pagar los salarios y remuneraciones de los funcionarios y servidores del Estado.

- Sufragar los gastos militares.

- Proporcionar espectáculos públicos.

- Construcción de edificios y obras de ingeniería de uso público.

- Reparticiones de alimentos e incluso dinero en la capital del Imperio.

\section{LOS IMPUESTOS}

Por el término "Publicum", los autores latinos y las inscripciones designan el impuesto, establecido por el Estado y recogido como propiedad pública. Este impuesto, a su vez recibía otros nombres:

"Tributum", "Stipendium», "Vectigal»: En un principio tanto el término como el concepto de impuesto no estaba bien definido entre los romanos, utilizándose estas palabras en un sentido relativamente impreciso.

El término "Tributum" proviene de tribu e indica en cierto modo su origen impositivo a las tribus dominadas a las que se obligaba a pagar un impuesto de guerra. Sinónimo en su origen: «Stipendium" o Sueldo, consistía en una especie de préstamo forzado a los vencidos para pagar al ejército vencedor. Es decir, cuando este impuesto estaba simplemente dedicado a mantener y pagar a las tropas, se denominaba "Stipendium".

Se puede considerar, pues, que "Tributum" y "Stipendium", fueron en sus orígenes una contribución de guerra establecida desde los primeros tiempos por los romanos a los pueblos conquistados. Este iba, a veces, seguido de la concesión de cierto grado de autonomía. Más adelante, las referencias que encontramos sobre "Tributum» y "Stipendium» hacen deducir que eran impuestos directos sobre personas o sobre propiedades.

En épocas excepcionales se podía establecer un tributo extraordinario («Tributum Temerarium») como un pago extraordinario realizado al Estado ${ }^{2}$.

2 Sobre la economia romana y su relación con el Estado, entre otros Ver: CraWFORD, M.H.: L'Imperio romano e le strutture economiche e sociali delle province. Como, 1986; DUNCAN-JONES, R.: The Economy of the Roman Empire. Quantitative Studies, Cambridge, 1982; CORBIER, M.: 
El tributo exigido por la renta y posesion ("Possesio») del suelo, público o privado, se denominaba "Vectigal».

Estos tres términos fueron empleados, en principio indiferentemente, como los epítetos: "Vectigalis», tributarius" y "Stipendiarius», aplicados, por extensión, a los pueblos, a las ciudades y a los hombres ${ }^{3}$.

\section{LOS IMPUESTOS DIRECTOS}

El "Tributum in capita" ya estaba instituido en la República romana, establecido según el recuento o empadronamiento, ("Census") del censor. Posiblemente, este tributo se impuso con el censo, pues la institución de la más antigua "capitatio» romana podría remitirse a tiempos de la monarquía, aunque sin ninguna confirmación histórica ${ }^{4}$. Gracias al censo, el Senado estimaba la fortuna total de los ciudadanos - Donde no estaban comprendidas las tierras del «Ager Publicus» ocupadas por los mismosy establecian la cuota correspondiente a pagar en un tanto por mil: "Tributum simplex, duplex o triplex» 5 .

En el 182 a.C., Catón el Censor duplicó la valoración de ciertos objetos de lujo y de esclavos al considerar la fortuna de los ciudadanos y fijó los

"Devaluations et fiscalité, (161-235)" en Les dévaluations à Rome: époque républicaine et Impériale. Roma, 1978; ANDREAU, J.: La vie financière dans le monde romain. Les métiers de maineurs d'argent, Roma, 1987; De MARTINo, F.: Historia económica de la Antigua Roma, 2 vol. Madrid, 1979; GARSEY, P. - SALLER, R.: El Imperio Romano. Economía, sociedad y cultura, Barcelona, 1991; LATOUCHE, R. Les origines l'economie occidentale, Paris, 1956; CLERM, E.: Sur les sociétés précapitalites, Paris, 1978.

3 No se sabe bien por qué, en los textos jurídicos se denomina a las tierras de las provincias senatoriales como "Stipendiaria" y a las de las provincias imperiales como "Tributarias": "Stipendaria sunt ea, quae in his provinciis sunt, quae propiae populi Romani esse intelleguntur; tributaria sunt ea, quae in his provinciis sunt, quae propiae Cesaris esse creduntur" Gai, 2 21; También en Dig. 7, 1, 7. Sobre la distinción y definición de "Tributum" y "Stipendium": GRELLE, I.: "Stipendium vel Tribiutum", Labeo, 12, 1966, pp. 209 y ss.

4 Una antiquísima "Capitatio" fue suprimida por Servio Tulio y restablecida por el segundo Tarquinio según narra Livio: “Estableció el censo, estimando el dinero y bienes que poseía cada ciudadano, institución de enorme utilidad para la futura magnitud de tal imperio, a partir de la cual las cargas militares y civiles se repartian no a tanto por individuo, como anteriormente sino según su capacidad económica; con base en el censo se pudo fijar las clases y las centurias, ordenamiento este brillante tanto para la organización militar como civil. "TITO LIVIO, 1, 42, 5."

5 Claro ejemplo es el tributo impuesto a doce colonias latinas que relata Tito Livio: "Aquel año el Senado acordó que se impondría y se recaudaría a estas colonias un tributo de un As por cada mil y se haría en ellas el censo según la fórmula establecida por los censores romanos -se quiso que fuese a misma que se aplicaba a la población romana- Los resultados serían presentados por los censores jurados de las colonias antes de abandonar su cargo". TITO LIVIO, 29, 15, 9; También IBIDEM: $23,31,1$ y $39,7,4$. 
tributos a tres por mil. Los ciudadanos cuya fortuna no ascendía a 15.000 ases fueron exentos de tributo y denominados "Proletarii" o "Capite census". Los que tenían una fortuna superior a dicha cifra eran" Adsiduus" o “Locuples". (Plutarco; Catón, Maj, 18, Tito Livio; 39, 44, 2 Ciceron; De rep., 2, 22, 40).

En todos los casos, el Senado se reservaba el derecho a decidir, aumentar o modificar los impuestos ${ }^{6}$.

Con el advenimiento del Principado, esta prerrogativa senatorial se mantuvo. Así Tiberio "consultaba al Senado sobre el establecimiento de los impuestos, de la cesión de los monopolios o reparación de edificios públicos», entre otras cuestiones (SUETONIO, Vita Caes, Tiberio, XXX).

Ello demostraria que el "Princeps" no era el único decisor y ejecutor de las finanzas del Estado ?.

Con Augusto, el censo en las provincias Imperiales era regulado ycontrolado directamente por los gobernadores provinciales y por los "Censitores" o "Legati ad census accipendos".

Estos fueron por lo general senadores, hasta Hadriano que pasaron a ser de rango ecuestre ${ }^{8}$.

Debieron existir "officinae» dedicadas especialmente al censo en las capitales provincias ("Tabularia"), donde trabajaban los empleados subalternos responsables del censo.

Estos y su función en las tributaciones son citados en las "Tabulae Tributorum» o Tabularium, (Lista censorial pública) que contiene un "Auditor tabularii", un "Dispensator a tributiis y otros "Tabularii", tal vez libertos y esclavos empleados en distintas funciones para la elaboración y aplicación del censo, («Auditores a comentariis», "Librarii», «Notarii», «Tabularii»...).

Los "Tabularii" recibian el pago de los impuestos, daban y archivaban sus correspondientes recibos.

6 NiCOLET, C.: Tributum. Rerecherches sur le fiscalité directe à l'époque Republicaine. París, 1976; También ver GoRdELIER, M.: Instituciones económicas, Barcelona, 1980.

7 Sobre el Fisco, sus diversos ingresos y su desarrollo a lo largo del Alto imperio hay tres magnificos estudios: El ya clásico de C.V.H. SUTHERLAND: "Aerarium and Fiscus during the Early Empire" A.J.Ph., LXVI, 1945, Pp. 151 y ss. Más recientes: MILLAR, F.: «The Fiscus in the first two centuries", J.A.S., 53, 1963, pp. 29-42; BRunT, P.A.: "The Fiscus and its Development", J.R.R., 56, 1966, pp. 75-85.

8 Ver PFLAUM, H.G.: Les Carrières procuratoriennes équestre sous le Haut-Empire romain, París, 1960-61; También ver: LouIS LUCAS, P. Etude sur la vénalité des charges et fonctions publiques et sur celle des officiers ministériels depuis l'antiquité romain jusqu'a nos jours, París, 1882. 
Estos archivos fueron decisivos en la administración imperial (registro de individuos, de nacimientos, estimación de bienes y fortunas, recaudación y repartición de tributos).

Augusto estableció dos clases de tributos: Por persona física («Tributum capitis») y el impuesto por la propiedad territorial ("Tributum soli»).

Siendo el "Tributum capitis" o "Capitatio» un impuesto a la persona, estaba considerada como una especie de servidumbre y sólo fue remitido a los no ciudadanos.

Es posible también como parece desprenderse de un pasaje atribuido a Ulpiano, que la "Capitatio" se estableciera como un suplemento del impuesto del suelo, ("Tributum soli») Dig, 50, 15, 3-4).

Sin embargo la «Capitatio» recayó sobre todo a población rural de condición humilde: pequeños propietarios y colonos a quienes siquiera la "Constitutio Antoniniana" de Caracalla libró de su carga ${ }^{9}$.

Desconocemos con exactitud la cantidad y el tipo de impuesto que se pagaba por la propiedad mobiliaria. Sabemos que los pequeños comerciantes ("Homines negotiantes") debían pagar también su tributo («Aurum negototiatorum"), de acuerdo con las ganancias de sus negocios, existiendo un impuesto especial para los banqueros, tal vez similar a la propiedad del suelo ${ }^{10}$.

Recordemos también que los judios pagaban un impuesto especial («Fiscus ludaicus»), establecido por Vespasiano tras la represión de las revueltas de los judíos y la destrucción del Segundo Templo. Los dos dracmas que aquellos pagaban al templo de Jerusalén, pasaron a ser entregadas a Júpiter Capitolino ${ }^{11}$.

El cobro del impuesto sobre la propiedad territorial pasa a ser recaudado por procuradores imperiales y gobernadores senatoriales.

Tales impuestos estaban establecidos como una parte alícuota de las propiedades que el mismo propietario declaraba y del producto logrado de la misma (Un quinto, un séptimo o un décimo de su cosecha).

9 Clark, C-HASWELL, M.: The economics of subs istence agriculture, Londres, 1970. Sobre la Constitutio Antoniana sigue siendo un estudio muy completo el de SASSE, C.H.: Die Constitutio Antonianiana. Eine Untersucqunq über den Umfanqder Bürgerrechtsverleihung auf Grund des Pap. Giesen 40, Wiesbaden, 1958; Trade and famine in classical Antiquity, ed. P. GARNSEY-C.R. WHITAKER, Cambridge, 1983.

10 Sobre la banca romana: ANDREA, J.: “Histoire des métiers bancaires et evolution économique", Opus, 1984, 3, pp. 99-114; Ibidem: "Modernité économique et statut des maniers de l'argent", MEFR, 97, 1985, pp. 337-410.

11 Sobre la condición jurídica y económica de los judios: JUSTER, J.: Les juifs dans l'Empire romain: leur condition juridique, économiqiue et sociale, Paris, 1914; Más reciente SMALLWOOD, E.M.: The Jews under Roman rule, Leiden, 1976. 
En época republicana, los encargados de recaudar los impuestos eran los «Publicani».

Aunque este término podía ser extensivo y válido a todos los que estaban al servicio del Estado, los textos designan así a los recaudadores de impuestos, tanto directos como indirectos.

Como esta actividad era denegada a la dignidad de los senadores, tales puestos fueron acaparados por los equites, que formaron una "clase especial" ("Ordo Publicanorum").

Estos «Publicani» actuaron en sociedades repartidas en las provincias.

Cada sociedad tenía su máximo administrador en Roma, el cual como principal representante ("Magister») negociaba con el Estado Romano las recaudaciones exigidas que la sociedad debía entregar al mismo ${ }^{12}$.

El "Magister" delegaba su autoridad en las provincias en el "Pro magistro", el cual dirigía toda una red de subalternos encargados de la recaudación tributaria, la contabilidad, transmisiones etc...

Las ganancias de estas sociedades fueron tan importantes y notables como la fama de su avaricia y usura. Ambos fueron factores decisivos para provocar el odio popular.

Ello, unido a los fraudes y estafas de estas sociedades de Publicani, dieron lugar a que ya Augusto, iniciara su destitución por funcionarios imperiales y que Nerón tomara nuevas medidas para evitar sus abusos, aunque subsistieron en las provincias senatoriales hasta las modificaciones realizadas por Ulpiano durante el principado de Alejandro Severo.

El fisco recibía el impuesto de las provincias imperiales e, incluso, una parte del impuesto recaudado de las provincias senatoriales, al menos a partir de la dinastía Flavia.

La recaudación de los impuestos estaba establecida por distintos urbanos a través de los "Tabularii municipales" y se realizaba a través de las ciudades y las capitales de provincias ${ }^{13}$.

El «Tabularius» era un cargo («Munus»), en principio personal y que debía ser pasar de forma correlativa sobre los distintos ciudadanos.

12 Según: Cimma. M.R.: Ricerche sulle societá di Publicani. Roma, 1981.

13 GarzetTI, A.: "Aerarium e Fiscus sotto Augusto; storia di una questine in parte di nomi", Atehaeum, XXXI, 1953, pp. 298 y ss.; SutHERLAND, C.H.V.: "Aerarium and Fiscus during the Early Empire", A.J.Ph., 1945, pp. 151, y ss. JonES, A.H.M.: "Aerarim and the Fiscus", J.R.S. XL, 1950, p. 25. 
A partir del siglo III recayó exclusivamente sobre los decuriones («Exactores tributorum»), a los cuales el gobierno de Roma les imputó la responsabilidad de estas recaudaciones pero también consiguieron importantes dispensas.

Una gran parte de los impuestos cobrados por los funcionarios municipales en sus ciudades eran recogidos por los Procuratores Imperiales o los agentes senatoriales a través de sus "Exactores tributorum», que eran esclavos imperiales o esclavos públicos, que enviaban lo recaudado al "Fiscus".

Además de estas cargas fiscales impuestas por el Estado, los gobiernos locales tenían que ocuparse de cobrar y administrar otros «impuestos municipales" para sufragar los gastos propios de una administración ciudadana: mantenimiento de edificios públicos, preservar el orden público, organizar festividades locales, representación ciudadana y judicial, etc... ${ }^{14}$.

Hemos de tener en cuenta que la ciudad era el núcleo de la cultura y la vida pública económica romana. En ella confluían las exigencias de los gobiernos central y local. Sede y centro de actividades culturales y económicas, la ciudad era el núcleo de afluencia de producción y de mercado, pero también su protagonismo generaba gastos y presupuestos un tanto elevados.

Todos estos gastos públicos muchas veces no podían sostenerse con la financiación que proporcionaban los impuestos locales, si añadimos además que la facultad de las ciudades para reglamentar sus propias finanzas se encontraba restringida por directrices imperiales, pues ninguna ciudad podía exigir nuevos impuestos sin permiso especial del gobierno de Roma.

También tenían otras limitaciones como la prohibición de erigir edificios públicos sin la autorización imperial.

Por todo ello, las ciudades tenían que valerse de la munificencia privada.

La institución que contribuyó notablemente a ayudar a las exigencias de estos gobiernos locales y ciudadanos fue la "Liturgia" en administraciones de tradición griega y el "Munus» y el "Patronatus" en territorio

14 Ver Johnson, A.C.: Municipal Administration in the Roman Empire. Princeton, 1926; También: Gascou, J.: La politique municipale de l'Empire romain en Afrique proconsulaire de Trajan à Septime-Sèverè, Roma, 1972; Rodriguez NeliA, J.F.: "Las elecciones municipales en la Bética romana", Actas del / Congreso de Historia de Andalucia. Andalucia en la Antigüedad, Córdoba, 1978, pp. 170 y ss. AbAsCAL, J.M. - EsPInOSA, U.: La ciudad hispano-romana. Privilegio y poder, Logroño, 1989, pp. 111-149; CRAWFORD, D.J. ed.: L'imperio romano e le strutture economiche e sociale delle province Como, 1986. 
latino, que para muchos autores fueron una de las causas de la decadencia y ruina de las ciudades.

Estas instituciones, en líneas generales consistian en que los miembros más acomodados de una comunidad se responsabilizaban de ciertos servicios que ellos mismos costeaban. También muchos de estos ricos ciudadanos dedicaban no sólo su dinero sino su tiempo a la ciudad, desempeñando magistraturas y cargos locales.

Por otra parte a los poderosos les convenía mantener la debilidad económica municipal, siempre insuficiente con los impuestos locales, gracias a la cual tenían que recurrir a su ayuda y aportaciones puesto que ello contribuía a sostener su poder e influencia en la vida pública y ciudadana ${ }^{15}$.

Un impuesto directo ya percibido en época republicana en especie era la Annoa, establecido en forma de diezmo ("Decuma"), en muchas provincias, asentado según un censo ("Tributum ex censu») e instituido por decisión del Estado Romano.

Este impuesto se denominaba también "Aestimatum» o "Vectigal».

Desde comienzos del Imperio, ya desde Augusto aparece el término «Annoa», "Annonaria fuctiones» o «Annonaria species», aplicado a este impuesto.

La Annona era recaudada en las provincias en almacenes públicos, siendo los gobernadores provinciales los responsables de la misma. En cada almacén público había un sistema de pesas y medidas, destinado a prevenir los fraudes. Este impuesto fue empleado en el Imperio en dos formas:

- Annona Militaris, destinada a sufragar los gastos militares y de los funcionarios del Estado y que recibían de acuerdo con su dignidad («Annonas suae congruas dignitati», Cod. Theod. VII, 4) ${ }^{16}$.

15 Las fuentes juridicas del siglo II d.C. revelan la existencia de hombres cuya riqueza y posición social les colocaba por encima de otros oligarcas locales, al ser lideres cívicos. Sobre las atribuciones de estas oligarquias municipales Cf. r. SALLER, R.P. "Patronage and promotion in equestrian careers", J.R.E., 70, 1980, pp. 44-63; JACQUES, F.: Le privilège de liberté: Politique impériale et autonomie municipale dans les cités de l'Occident romain, París, 1984. También: VEYNE, P. La société romaine, París, 1990, pp. 57 y ss.; Alföldy, G.: Historia social de Roma, Madrid, 1987, pp. 167 y ss.; GAGE, J.: Les classes sociales dans l'Empire Romain, Paris, pp. 165-169; GauthiER, PH.: "Las cités grecques et leurs bienefacteurs", BCH, Supl. XII, París, 1985; También JaCQUES, F.: Le privilège de la liberté: politique impériale et autonomie municipale dans les cités de l'Occident romain, París, 1984; LANGHAMMER, W.: Die rechtliche und soziale Stellung der magistratus municipalis und der Decurions, Wiesbaden, 1973.

16 Sobre la Annona, la producción y la distribución de trigo en Roma hay una abundante bibliografia. Ver entre otros: Armées et fiscalité dans le monde antigue, Paris, 14-16 oct. 1976, 
Más adelante, este tipo de prestación fue reemplazado por dinero, («Adaeratio»), como prestación para alimentación ("Cellaria»: pan, carne, aceite, vinagre, vino y sal) y forraje: («Capita»: leña y vestido).

Los funcionarios militares («Primipilari», «Actuarii» y «Subcribendarii»), eran los encargados de recoger la "Annona militaris" y repartirla en el ejército según lo establecido en las constituciones imperiales.

En otras provincias este tipo de tributo establecía otras prestaciones como era el alojamiento a los soldados, proporcionar caballos y carros e incluso metales para el armamento del ejército que se fabricaba bajo la dirección del prefecto del pretorio por los «Magistrati officiorum».

- La segunda aplicación del impuesto de la "Annona» era el avituallamiento de Roma ("Annona civica»).

En las provincias de Galia e Italia este impuesto se unía al «Tributum ex censu». Durante el Alto Imperio la "regio annonaria" por excelencia fue Italia. En el resto de las provincias se cobraba un impuesto sobre la propiedad territorial tanto en dinero como en especie que ascendía a la quinta, séptima o décima parte de la cosecha. A lo largo del Imperio este tributo "ex censu», se extendió a todas las provincias excepto Egipto donde salvo los dominios que pertenecían a los templos, el suelo de Egipto se consideraba como "Patrimonum Principis", es decir, dominio particular de príncipe, como sucesor de los Lágidas ${ }^{17}$.

\section{LOS IMPUESTOS INDIRECTOS}

El término Vectigal, cuya etimología procede tal vez de la palabra "Vehere»: Transportar, se refería a la renta, en dinero ("Vectigalia pecunia") o en especie, que pagaban al Estado los arrendatarios o usufructuarios de algún dominio público: Tierras, («Ager vectigalis") puertos, aguas fluviales, pastos, minas y salinas (Saliane, Scriptura).

1977; Humbert, G. “Annona”, en Daremberg Saglio, pp. 273-280; D. VAN BERCHEN: Les distributions de blé et d'argent à la plèbe ronain dans l'Empire. Paris, 1939, D'Escurac, P.: La préfecture de l'Annone, service administratif impérial d'Auguste à Constantin, París, 1976; Sobre la Annona militaris ver Armées et fiscalite dans le Monde Antique, París, 1978; GentRY, A.P.: "Roman military stone built granaries in Britain", BAR, 32, 1976.

17 S.L. WALLACE Taxation in Egipt from Augustus to Diocletian, Princeton, 1938. También: Bowman, A.K.: Egipt after the Pharaons. 332 B.C.-A.D. 642, Berkeley and Los Angeles, 1986. 
Más tarde así se denominaba a la renta percibida en una provincia por un magistrado ("Vectigal praetorium aedilicium») o la contribución destinada al pretor o a los ediles por su ayuda en los juegos de Roma.

Aunque el término Vectigal se utilizó, en principio, para denominar todo impuesto debido al Estado como indicamos anteriormente, finalmente se designó con esta palabra, básicamente a los impuestos indirectos cuyo cobro según la tarifa establecida previamente por el Estado, era adjudicado en subasta a sociedades capitalistas de publicanos que negociaban e incluso llegaban a adelantar la cantidad a percibir por los mismos al Estado, consiguiendo con ello importantes beneficios ${ }^{18}$.

Debido a que en la ideología romana, el impuesto directo ("Tributum»), era considerado como algo indigno para un ciudadano libre, este no tuvo un gran desarrollo y la administración romana tuvo que acudir fundamentalmente a los impuestos indirectos para llenar las arcas públicas.

Con el término vectigal se designan impuestos distintos, en su mayoría indirectos pero diferentes entre sí por su naturaleza, importancia, percepción y administración. Enumeramos los que tuvieron más notoriedad entre ellos:

- PORTORIA: Sobre aduanas y peajes.

- VECTIGAL ROTARIUM: Sobre la circulación de vehículos.

- AURUM VICESIMARIUM: Sobre la manumisión de los esclavos.

- VICESIMA HEREDITATIUM: Sobre las herencias.

- CENTESIMA RERUM VENALIUM: Sobre las ventas en general, siendo sus impuestos más sobresalientes:

* QUINTA ET VICESIMA VENALIUM MANCIPIORUM: Sobre la venta de esclavos.

* ANSARIUM o ANSARIA PECUNIA: Sobre las ventas de mercancias en los mercados públicos.

- QUADRAGESIMA LITUM: Sobre los procesos judiciales.

18 TITO LIVIO denomina como Vectigal el impuesto de guerra pagado en dinero por Cartago a Roma tras la Segunda Guerra Púnica: “... Declaró Anibal ante la asamblea que el Estado tendría recursos suficientes para hacer efectivo el "vectigal" debido a los romanos, sin imponer contribuciones a los particulares, si se exigía todo el dinero atrasado; y cumplió lo prometido". TiTo LIVIO, $A b$ Urbe condita XXXIII, 47.1. Los Publicani donaban al Estado una parte de la recaudación de los tributos, quedándose con el resto en beneficio propio. Los textos literarios y la epigrafía nos ha dejado testimonios de la excesiva liberalidad e incluso corrupción de recaudadores de impuestos. 


\section{Portoria}

Con el término "Portorium», derivado de "portus", se designaba al impuesto indirecto sobre el transporte de mercancías y personas que debía pagarse al pasar por determinados establecimientos y fronteras en el territorio romano.

Es muy difícil diferenciar los distintos tipos de "Portoria" tanto por el concepto sobre el que se basaba su ubicación como por las condiciones que estos estaban establecidos ${ }^{19}$.

El propio Estado Romano sólo hacía diferenciación entre los "Portoria" terrestres y marítimos. Aún así, se podrían definir ciertos tipos de tasas según la frontera al que pertencía:

- Las establecidas como aduanas en las antiguas fronteras de los países conquistados.

- Las concesiones de paso, establecidos en los límites municipales.

- Los peajes o tasas sobre mercancías establecidas en lugares determinados en las ciudades.

Los propios textos jurídicos romanos no aciertan a determinar en muchas ocasiones, las clases y diferencias de estos tipos de impuestos. La causa principal tal vez fuera que tanto la permanencia como el asentamiento de estos límites de peaje se realizaron de una forma irregular durante el expansionismo del Imperio, sin que se determinara para los mismos unas ciertas disposiciones que los regulara y organizara.

Por 10 general, todos los objetos destinados al comercio estaban sometidos al pago de «portorium». Incluso pagaban este impuesto las mismas personas que los trasladaban.

Así fue establecido durante la República perdurando durante el Imperio con pocas modificaciones.

Gozaban de franquicia el personal y los objetos al servicio del Estado romano o considerados como instrumento de trabajo y de uso particular. Se establecían así estas excepciones:

19 Sobre los Portoria DE LAERT, S.J.: Portorium. Etude sur l'organisation douanière chez les romain surtout à l'époque du Haut Empire. Gand, 1949; Sobre los impuestos indirecto en general ver también VITTINGHOFF, en R.E., XXII 368 f.; GaRnSEY, P.: "Taxatio and Pollicitatio in Roman Africa", J.R.S., 1971, pp. 61 y ss.; Sobre las fronteras y los impuestos arancelarios:; JONES, G.B.D.: "Concept and development in Roman frontiers", Bull. Ryl. Libr., 60, 1978, pp. 116-144; MITCHELL, S.: "Requisitioning transport in the Roman empire: A new inscription from Pisidia", JRS, 66, 1976, pp. 106-131. 
- Quienes pertenecieran a la familia y casa del Emperador.

- Los embajadores de naciones extranjeras.

- Los magistrados encargados de transportar los animales y objetos destinados a los espectáculos públicos.

- «Instrumenta militaris»: Todo el personal, los instrumentos y carrería del ejército.

- "Instrumenta itineris» o medios de transporte carros, animales decarga y correajes.

- «Instrumenta agricolae». Objetos de trabajo para la agricultura».

- Los «navicularii».

Las sociedades de "Publicani" se encargaban del cobro de los "Portoria", como del resto de los impuestos romanos. Sus recaudadores se denominaban "Conductores portorii», que como las demás sociedades capitalistas tenian su "Magister" en la capital y su representante "Pro magistro" en las provincias. Bajo las órdenes de este último se encontraban una serie de personal especializado: "Manceps", "Tabellarii", «Portitores».

Como la recaudación de los demás impuestos, los «Portoria» proporcionaban importantes beneficios. Los "Conductores portorii». Existían disposiciones legislativas sobre la imposición y ejecución de tasa y aduanas.

Había que hacer una declaración de todos los objetos que se transportaba, mercancias de comercio y de uso personal, ("Sive venalia, Sive usualia"). Se debía pagar una parte proporcional a la cantidad y el valor de la carga (Vicésima, quadragésima, quinquaesima).

El declarante podía ser registrado por empleados de la misma aduana «Scrutatores»), que asegurasen la veracidad de su declaración. En caso afirmativo, se registraba el número de objetos de peaje y la suma pagada por los mismos. Si la declaración era negativa, los objetos no declarados podían ser requisados so pago de una transación o multa en beneficio de los empleados.

Las tasas que se conocen de época republicana son muy numerosas. Durante la dictadura de César se tomaron una serie de medidas sobre las mercancías extranjeras y sobre las importaciones. Medidas que, en líneas generales, continuaron con el advenimiento del principado ${ }^{20}$.

20 Sobre el comercio, la importación, exportación y el transporte de mercancias en general: D'ARMs, J. H.: Comerce and social standing in ancient Rome, Cambridge-Massachusetts, 1981; 
Según Tácito (Ann. XIII, 50-51) en el año 58 d.C., Nerón intentó suprimir los «Vectigalia», posiblemente, se refería a los tributos de transporte, es decir los referentes al «derecho de portazgo». Tales medidas fueron tomadas "antes las repetidas reclamaciones del pueblo romano que portestaba de los abusos de los publicani». "... Pero le convencieron sus consejeros de más edad porque si se suprimían estos «Portoria», se pediría luego la abolición de los demás tributos, advirtiéndole que el imperio se desharía si las rentas de que se sostenia la "República" se vieran disminuidas" (TÁcITO, Ann, XIII, 50).

Sin embargo, fue en el gobierno de Nerón cuando se establecieron una serie de disposiciones para «moderar la codicia de los publicanos» y proteger a los individuos, principalmente los comerciantes, de los abusos de «Conductores» y «Scrutatores» con leyes que castigaban a los mismos:

«El príncipe ordenó por un edicto que se fijaran en lugar visible todas las leyes fiscales, mantenidas ocultas hasta la fecha, que las exacciones omitidas no pudieran reclamarlas después de un año, que en Roma el pretor y en las provincias los que actuaran de propretores o procónsules dictaran sentencia en las causas contra los publicanos, sin hacerlas guardar turno, que a los militares se les conservara su inmunidad, salvo en las cosas con las que negociaran. Seguian otras disposiciones muy justas que fueron observadas durante breve tiempo para luego quedar sin fuerza. Ha permanecido en vigor la abolición de la cuadragésima, quinquagésima y demás títulos excogitados por los publicanos para exacciones ilícitas. En las provincias ultramarinas, se atemperó el impuesto sobre el transporte de trigo - para el suministro de Roma-y se estableció que en los censos de los traficantes, ("Naviculari"), no se incluyeran sus naves ni pagaran tributos por ellas" (TÁCITO. Ann., XIII, 51).

A partir de estas disposiciones, en cada peaje y aduana debían fijarse públicamente las tasas y precios. Si alguien se consideraba injustamente cobrado podía pedir justicia. El publicano hallado en falta debía devolver el doble de lo percibido, y si se demostraba que había habido violencia, el triple.

En el 193 d.C. Helvio Pertinax (HeRodiano, II, 4-7) hizo remitir muchas tasas impuestas por sus predecesores en las desembocaduras de los ríos,

Roman Seaborne commerce, ed. D'Arms y Kopft, MAAR, 36, Roma, 1980; HuveLIN, P. Etudes d'histoire du droit commercial romain, Paris, 1984; FeUvaIER-PREVOTAT, CL.: "Mercator et negociator dans le discours cicéronien, essai de définition", DHA, 7, 1981, pp. 367-406; también VALENCIA, M. "Mercator y negotiator. Ambigüedad y realidad económica en la obra de Cicerón", Cesaraugusta, 55-67, 1989-90, pp. 195-216; PANLELLA, C.: “Retroterra, porti e mercat, l'esempio dell'ager falernus", MAAR, 36, 1980, pp. 251-260; RoUGE, J.: Recherches sur l'organisation du commerce, París, 1966. 
en las entradas de las ciudades e incluso en ciertas rutas, logrando asi cierta apertura en el movimiento comercial. Es muy posible que se hubiera llegado situación de abusos y saturación de zonas de "Portoria» en las vias comerciales. Muchas de éstas habian sido establecidas por decisión de Commodo, antecesor de Pertinax ${ }^{21}$.

\section{Aurum Vicesimarium}

El Aurum Vicesimarium o Vicesima Libertatis era otro impuesto indirecto de carácter suntuario que debía pagarse al Estado cuando un esclavo era manumitido. Su tasa era una vigésima parte del valor venal del esclavo. Fue establecido en el 357 a.C. por el cónsul Cn. Manlio Capitolino, mediante la "Lex Manlia", ratificada por el Senado, como se desprende el pasaje de Tito Livio:

“Este cónsul no hizo nada de mención, a no ser la presentación de una ley a los soldados, en una innovación sin precedentes, en el campamento de Sutrio, para que la votaran las tribus, referente a un impuesto del cinco por ciento de las manumisiones. Los senadores, como una ley semejante proporcionaban al erario de escasos fondos, unos ingresos nada despreciables, la ratificaron" (TITO LIVIO, VII, 167).

Este impuesto fue doblado por Caracalla, restituyendo Macrino su antiguo valor, desapareciendo en la época de Diocleciano, como otros impuestos indirectos ${ }^{22}$.

Con frecuencia, era el propio esclavo quien pagaba el impuesto debido a su libertad de su propio pecunio, aunque también podía suceder que el patrón pagara una parte de este impuesto.

Cuando la manumisión era dada por testamento, el testador legaba a su liberto la liberación de esta deuda, o bien, delegaba en sus herederos el pago de la misma a los "Publicai libertatis" o "Socii vicessima libertatis", encargados de su recaudación Cuando a mediados del siglo II, pasó al fisco, fueron funcionarios imperiales, como procuradores de rango

21 Sobre el abuso de los "Publicani» que cobraban los «Portoria" citan los juristas: "Quantae audaciae, quantae temeritatis sint publicanorum factiones, nemo est qui nesciat", Digst., XXXIX, 4 ,

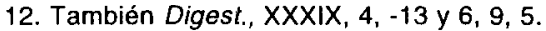

22 GIACCHERO, M.: Edictum Diocletiani et collegarum de pretiis rerum venalium, Genova, 1974, 2 vol. También ver los estudios de Bravo, G.: Coyuntura sociopolítica y estructura social de la producción en la época de Diocleciano. Génesis de la sociedad bajoimperial, Salamanca, 1980; Ibidem: Diocleciano y las reformas administrativas del imperio, Madrid, 1988. 
secundario quienes se encargaron de controlarlo en el denominado «Ficus libertatis et peculiorum» ${ }^{23}$.

El Aurum vicesimarium aportaba una suma tan considerable al Fiscus romano que se creó un tesoro especial para percibir el mismo: "Aerarium Sanctius", que era un tesoro extraordinario, establecido en el "Sancta Santorum" del templo de Saturno, destinado a guardar el oro que sólo podía ser empleado para las necesidades extremas y urgentes del Estado Romano.

Por ello, es posible que este impuesto debiera pagarse en oro, o, al menos era convertido automáticamente en lingotes de dicho metal para guardarse en el "Aerarium Sanctis».

\section{Vicesima Hereditatum}

Fue Augusto quien instituyó el impuesto indirecto sobre las herencias: Les lulia de Vicesima Hereditatum, en el año 6 a.J., ya proyectado según Apiano por Julio César y los triunviros (Apiano, Bell. Civ., V, 67).

Este impuesto consistía en cobrar un $20^{\mathrm{a}}$ parte de cada una de las herencias que se tramitaban. El destino del capital obtenido estaba destinado a alimentar la caja del "Aerarium militare", cuyo tesoro aseguraba, principalmente, la pensión de los soldados veteranos.

La propia ley contemplaba dos excepciones que escapaban del pago de este impuesto:

- Los parientes más cercanos, posiblemente los que en el derecho romano se denominan como "Decem personae" (padre, madre, hijos, abuelos y hermanos).

- Aquellos que la ley consideraba como más necesitados, los ciudadanos que poseían menos de 100.000 sestercios.

Este tipo de excepción sólo beneficiaba a los ciudadanos "optimo iure" que además no hubiesen alcanzado la ciudadanía, a través de «lus latii» ni a través de la manumisión, es decir, eran ciudadanos romanos de antigua ascendencia.

23 Asi Trimalción indica en su testamento el pago del "Aurum Vicesimarium" de todos los esclavos que quiere manutimir "para que me quieran ahora lo mismo que si ya hubiese muerto". Petronio, Satyr., LXXI. También Suetonio, Vespasiano, XVI; TÁito, Ann., XIV, 42; SeneCA, Epist., LXXX; PLINIO, Nat. Hist., VII, 40. 
Nerva disminuyó el rigor de esta ley, ampliando los beneficios de estas exenciones a todos los ciudadanos romanos y extiende este derecho de parentesco («lus cognationis»), es decir, permitir que los bienes fuesen trasmitidos de la madre a los hijos y de los hijos a la madre. Trajano siguió ampliando este favor entre los padres y los hijos.

Caracalla, en cambio amplió la tasa a pagar por la trasmisión de la herencia a una décima parte, suprimiendo todas las inmunidades otorgadas a este impuesto, siendo restablecidas por Macrino.

La "Vicesima hereditatum" desapareció con Diocleciano.

Este impuesto fue recaudado por los "Publicani" y más tarde por los procuradores provinciales. La dificultad de deducir y estipular su cobro, calculando las cantidades establecidas según el volumen de las herencias, hizo que su recaudación pasara a mediados del siglo II a unos procuradores especiales con rango de «Ducenarii», domiciliados en Roma ("Procuratores XX hereditatum»).

Ellos debian de conocer inmediatamente tras la muerte del testador, la cantidad de la herencia y las cuestiones acerca de la misma (gastos de entierro del difunto, y excepciones y disposiciones establecidas como usufructos, pagos, gastos..., etc.) ${ }^{24}$.

Las dificultades que tenía el cálculo y el cobro de este impuesto, justificarían la importancia y la preparación de sus Procuradores y el personal especializado a su cargo siendo, además calificado como uno de los principales centros de la administración estatal.

\section{Centesima rerum venalium}

También denominado "Vectigal Auctionum» y "Vectigal rerum venalium». Este impuesto indirecto fue establecido, con otros, por Augusto con el fin de llenar las arcas del "Aerarium militare".

Establecía el pago al Estado de la centésima parte sobre el precio de las mercancias que se vendian en subastas.

24 Casos especialmente difíciles era evaluar las herencias que dejaban obligaciones alimentarias de por vida a algunos beneficiarios en la misma, pues había que calibrar su coste y duración. Dig. $X X X V, 2$. Sobre las leyes testamentarias romanas Ver BIONDI, B.: Succesione testamentaria e donazione, Milán, 1960; DI PAOLA: Donatio mortis causa, Roma, 1969; WIEACKER, R.: "Erlass -Schenkung mortis causa und Liberatio fideicomissa", St. Grosso, 5, 1972, pp. 1 y ss.; MiQuel, J.: Derecho privado romano, Madrid, 1992, pp. 411-445. También: VisschER, F. DE: Le droit des Tombeaux romains, Paris, 1963. 
Su sucesor, Tiberio mantuvo este impuesto, pese a su impopularidad, aunque aceptó reducir considerablemente el mismo (Duocentesima):

«Quejándose el pueblo de la carestía de las vituallas, puso un precio más moderado, reduciendo la tasa en los mismos a los mercaderes que lo sacaban en la venta subasta” (TÁCITO, Ann., II, 42).

Calígula en los inicios de su principado suprimió este impuesto (Duocentesima) en Italia. Sin embargo, esta abolición debió durar poco. Incluso, según Suetonio, no sólo fue pronto restablecida sino que volvió a su antigua imposición (Centesima) junto con otros impuestos indirectos:

"Hizo satisfacer impuestos nuevos, desconocidos hasta entonces, los cobraban primero los recaudadores públicos; luego siendo inmensa la ganancia, hacíanlo los centuriones de las tribus de la guardia pretoriana; no hubo persona ni cosa a que se le impusiera gravamen. Estableció un impuesto fijo sobre todos los comestibles que se vendian en Roma..." (Suetonio, Vita Caes. Caius, XL).

El impuesto de la "centesima rerum Venalium» se mantuvo a lo largo del Principiado y en el siglo III es mencionado por Ulpiano. Cuando fue suprimido en el Bajo Imperio, tal vez por Constantino, la penuria económica que atravesaba el Estado Romano obligó a Valentiniano III a restablecer este impopular impuesto.

\section{Ansarium o Ansaria Pecunia}

También denominado «Vectigal Ansarii promercalium», por su relación con el impuesto "vectigal Foricularii promercalium», pagado por los mercaderes para adquirir derecho de "aposentación" de productos en los mercados públicos.

Es posible que su nombre derivara de los términos «Vasa Ansa", es decir, grandes contenedores donde se transportaban y colocaban los productos en venta.

Sin embargo, este impuesto indirecto, que se cobraba sobre la venta de dichas mercancías, expuestas por los comerciantes en los mercados públicos, no debe confundirse ni con el impuesto sobre el lugar que el vendedor ocupaba ni con la tasa sobre el precio de las mismas ("Centesima rerum venalium") ${ }^{25}$.

25 Sobre el comercio romano y sus leyes fiscales: ARMS, J. D.: Comerce and Social Standing in Ancient Rome, 1981; Hopkins, K.: «Taxes and trade in the Roman Empire", J. R. S., 1980, 70, 
Posiblemente fue Cayo Calígula el primero que dictó este tipo de impuesto indirecto sobre productos de consumo necesario y habitual («Edulia»), por lo que no sólo fue tremendamente impopular, sino que llegó a provocar durísimas protestas entre la población:

"Estableció un impuesto fijo sobre la venta de todos los comestibles que se vendían en Roma" (SUETONIO, Vita Caes. Caius, XL).

Según Marquand, el Ansarium era un impuesto que se pagaba al fisco por el comprador, en deducción de su precio de compra. Es posible que su recaudación, al menos en una gran parte, pasara a engrosar los fondos de la ciudad donde se comerciaban, aunque en tiempos de Marco Aurelio, se pusieron bastante reducciones a los beneficios municipales ${ }^{26}$.

Sin embargo, otros autores como Walter opinan que este impuesto se pagaría a modo de derecho de concesión para la venta de productos que Roma otorgaba y cedía en beneficio de la caja municipal. Tal vez esta interpretación estaría más acorde con la cita de Plinio sobre el Ansarium al que califica de «Portorium» (PLINIO. Nat. Hist., XIX, 4, 54-56).

A pesar de reiterados intentos que hubo para lograr la abolición de este impuesto, debido a su impopularidad y dureza, se mantuvo a lo largo del Imperio y en tiempos de Casiodoro, seguía vigente en la fiscalidad romana.

\section{Quinta e vicesima venalium mancipiorum}

Este impuesto indirecto exigia la vigésima quinta parte sobre el precio venal de un esclavo, que debía pagar en vendedor, pero que en la práctica éste lo incrementaba en su venta.

Con este impuesto Augusto y sus sucesores lograron recaudar importantes sumas con las que hacer frente a los gastos militares y conseguir fondos para los cuerpos de Vigilia (Dion Casio, LV; 31).

pp. 101-125; MoREL, J. P.: "Marchandises, marches, échanges dans le moinde romain", Annali de Seminario de studi del Mondo Antico, Archeologia e Storia Antica., 4, 1982; Ibidem: "La topographie de l'artesanat e du comerce dans la Roma antique", L'Urbs Espace urbain et Histoire, I a.C.-III ap. C., Roma, 1987, pp. 127-155; SchnuR, H. C.: “The economic Background of the Satyricon", Latomus, 18, 1959, pp. 790-829; DE MARTINO, F.: Nuovi studi di economia e diritto romano, Roma, 1988.

26 BeCken-MARQuAND: Handbuch Geschichte des röm., pp. 297, 320 y 331; HümBert, G. en Darember-Saglio, p. 280. 
Fue suprimido por Nerón:

“...También suprimió el impuesto de la quinta y vigésima sobre la venta de esclavos, algo que era más apariencia que realidad, pues al obligarse a pagar al vendedor, a los compradores se les incrementaba con el precio en otro tanto" (TÁCITO, Ann., XIII, 31).

Desde entonces, se reguló como impuesto sobre las ventas de mercancías que pagaban comerciantes y vendedores de las mismas (Centesima rerum venalium).

\section{Quadragesima Litium}

Eran los impuestos indirectos que se cobraban por los procesos judiciales. Dependían fundamentalmente, del desarrollo y decisiones establecidas por las leyes romanas.

En los procedimientos judiciales del derecho romano se distinguen dos procedimientos de ley:

- "Litis Contestatio": Donde se derivaba la organización de los diferentes procedimientos a seguir en un litigio y donde se determinaban las partes en instancia, el objeto y la naturaleza del juicio en cuestión.

Por lo tanto, se determinaba las diversas formalidades que exigian las acciones de la ley en cada caso específico.

- "Litis Aestimatio": Era la valoración pecuniaria del objeto en litigio, ésta podría hacerse o bien de acuerdo entre las partes, o bien judicialmente.

La "Litis Aestimatio" se contemplaba desde las vertientes civil y criminal ("Quaestiones perpetuae»). Fue aplicada en Roma desde fecha muy temprana. Concretamente, la "Litis Aestimatio" de carácter civil ya es citada en la Ley de las XII Tablas.

Es precisamente, a través de la "Litis Aestimatio» donde se procedía a la valoración de los objetos en litigio, de su duración y de sus costas. A través de dicho procedimiento se realizaban dos importantes cálculos que incidían en el pago del impuesto sobre el mismo:

* Por lo general, eran tres árbitros, establecidos por el derecho romano quienes procedían a evaluar en dinero, el valor venal del objeto causante del litigio, además de otros costes como el sistema judicial que 
debía llevarse a cabo y los perjuicios que todo este procedimiento podría haber causado.

* Se confería al juez, a través de ciertas fórmulas de la "Litis Aestimatio", el poder de condenar a una de las partes a pagar todos los gastos citados.

A partir de estas dos sentencias, se calculaban las cantidades de las costas y quién debía pagarlas. Tras ello, los funcionarios estatales correspondientes decidian a cuanto ascendían los impuestos indirectos derivados de estos procesos de justicia que exigían a la parte condenada a pagar los mismos ${ }^{27}$.

\section{CONCLUSIONES}

Con la génesis del Estado Romano, se inicia también la necesidad de cubrir los gastos que el mismo necesitaba para su desarrollo y mantenimiento.

Por ello, los primeros tributos fueron la exacción del vencedor romano sobre los pueblos sometidos, a los que obligaron a mantener los dispendios militares mediante unas cuotas más o menos preestablecidas:

"Tributum» y "Stipendium". Posiblemente a ello se deba el concepto del romano sobre el impuesto directo, considerado siempre como algo indigno del ciudadano "optimo iure» y propio de los dominados. Ésta es también la causa de que el sistema fiscal romano se desarrollara fundamentalmente a través de los impuestos indirectos.

A lo largo del período republicano, estos impuestos, se fueron regulando y estableciendo. A la vez que las propias Instituciones republicanas, las tributaciones sufrieron un lento deterioro, que exigía su revisión y reestructuración a las nuevas necesidades creadas en el Principado.

Por ello, Augusto modificó los impuestos directos y estableció nuevos impuestos indirectos, considerados necesarios para cubrir los numerosos gastos que el aparato estatal del Imperio Romano (ejército, burocracia, mantenimiento de la plebe...) exigía para su sostenimiento.

Sin embargo, el sistema fiscal romano nunca tuvo una organización ordenada y coherente. Ni siquiera con las modificaciones de Augusto y los príncipes Julio-Claudios, que se conformaron con realizar las reformas

27 Según: Murga: Derecho romano clásico. El proceso, Zaragoza, 1980; Gıofredı, L.: /l principi del diritto penale romano, Turin, 1970; BonıNı, J.: Ricerche di diritto giustiniano, Milán, 1968. 
más imprescindibles para la revisión del viejo sistema. En este período, se continuó con el mismo método de crear un nuevo impuesto para cubrir ciertas necesidades que generaban nuevos gastos. Es decir, los nuevos impuestos decretados debían cubrir unas exigencias concretas. Hasta Diocleciano y el advenimiento del Dominado, no se realizó una reforma completa del procedimiento fiscal romano.

Las nuevas cargas impositivas que, como era de esperar fueron medidas impopulares, por lo general, consiguieron cubrir las necesidades del Estado romano, por lo que, en su mayoría se mantuvieron durante todo el Alto Imperio, prueba de que las exigencias de los gastos estatales no disminuyeron precisamente.

Tampoco podemos negar totalmente que Augusto y sus sucesores, principalmente, Calígula y Nerón, alcanzaran ciertos logros e incluso, abrieran nuevas perspectivas fiscales.

Calígula estableció impuestos indirectos nuevos, como indica Suetonio, desconocidos hasta entonces, que cubrían todos los aspectos de la vida cotidiana romana, llegando, incluso, un mismo objeto o mercancía a tener varias cargas impositivas. Esto que en la actualidad nos parece una realidad normal, era algo desconocido en su tiempo.

Tal vez las reformas fiscales intentadas en el gobierno de Nerón, buscaran otras ordenanzas tributarias con diferentes orientaciones, además se intentó corregir y sanear la estructura fiscal romana, Tácito cita interesantes modificaciones, ya comentadas, que, por lo general, no tuvieron éxito. (TÁCITO, Ann., XIII, 50-51).

Es importante señalar que entonces se hicieron públicas las leyes fiscales y que de forma definitiva la recaudación tributaria estuvo a cargo de personal especializado de la administración romana, logrando en gran parte que disminuyeran los abusos de "Ordo publicanorum", sociedades capitalistas con más afán de lucro que de servir al Estado y que alcanzaron un alto grado de corrupción según narran las fuentes.

Vespasiano tuvo que proceder a sanear las finanzas públicas ( Patrimonium»). Hizo realizar una cuidadosa y exhaustiva revisión del censo. Aunque el fin primordial del mismo fue conocer cuales eran los dominios estatales que los particulares se habian apropiado indebidamente, esta información fue valiosisima en la recaudación tributaria. Creó nuevas contribuciones. Las más conocidas fue el "Fiscus ludaicus", ya citado y otros impuestos indirectos como el famoso "Vectigal urinae", sobre el uso de las letrinas públicas. También aumentó algunos de los 
impuestos ya establecidos. Todo ello le valió su fama de «avaro» entre el pueblo romano ${ }^{28}$.

El sistema fiscal establecido en el siglo I d.C., se mantuvo básicamente hasta el siglo III.

Podría decirse que la estructura impositiva iniciada por el Estado Romano fue la base y el punto de partida del sistema fiscal romano occidental.

Pero a pesar de las reformas realizadas, el peso de los impuestos cada vez fue más oneroso e intolerable. Al romano, como el hombre de hoy, siempre le pareció excesiva la recaudación de impuestos por parte del Estado. Así comentaba Suetonio de estos abusos: "No hay persona ni cosa que no se impusiera gravamen" (SUETonio, Vita Caes., Cayo, XL).

28 "No satisfecho, en efecto con restablecer los impuestos abolidos en tiempos de Galba, de crear otros y de los más gravosos, de aumentar los tributos de las provincias y de duplicarlos algunas veces, realizó a menudo tráficos deshonrosos hasta para un particular, comprando, por ejemplo, ciertas cosas en conjunto, con el único objeto de venderlas más caras al menudeo". SUETONIO, Vita Caes., Vespasiano, XVI. 